\title{
Produção de mudas de cafeeiro em função da época e da adubação
}

fosfatada

Production of coffee seedlings depending on season and phosphorus fertilization

\author{
Ronaldo dos Santos Monteiro 1 \\ Graduado em Agronomia, Universidade Federal da Paraíba, Centro de Ciências Agrárias, Campus II \\ E-mail: ronaldomonteiro@outlook.com.br
}

Vinicius Evangelista Alves Oliveira 2

Msc. em Agronomia, Universidade do Estado da Bahia, Departamento de Tecnologia e Ciências Sociais, Campus III

E-mail:vinicius_oliver17@hotmail.com

Altamiro Oliveira de Malta 3

Msc. em Agronomia, Universidade Federal da Paraíba, Centro de Ciências Agrárias, Campus II

E-mail: altamirol@ig.com.br

Walter Esfrain Pereira 4

Prof. Dr. do Departamento de Ciências Fundamentais e Sociais, Universidade Federal da Paraíba, Centro de Ciências Agrárias, Campus II

E-mail: walterufpb@yahoo.com.br

Josevan de Andrade Silva 5

Graduando em Agronomia, Universidade Federal da Paraíba, Centro de Ciências Agrárias, Campus II E-mail: josevanagro2012@hotmail.com

\author{
Alan Oliveira de Malta 6 \\ Graduando em Agronomia, Universidade Federal da Paraíba, Centro de Ciências Agrárias, Campus II \\ E-mail: alan-oliveira@live.com
}

Resumo: A produção de mudas é crucial para o estabelecimento da cultura do café. Diante disso, o objetivo desse trabalho foi avaliar o crescimento de mudas do cafeeiro arábica (Coffea arabica L.) em função da época e doses de fósforo. O experimento foi realizado em casa de vegetação do Departamento de Fitotecnia, pertencente ao Centro de Ciências Agrárias (CCA), da Universidade Federal da Paraíba (UFPB), Campus II, Areia, PB, realizado no período de 16/12/2013 a 16/06/2014. Foram utilizadas sementes de plantas matrizes de café arábica. Utilizou-se o delineamento em blocos casualizados (DBC), com quatro tratamentos e quatro repetições, com duas plantas por parcela. Os fatores consistiram no tempo $(30 ; 60 ; 90 ; 120 ; 150$ e 180 dias) e doses de fósforo $(0,0$; 0,$3 ; 0,6$ e $0,9 \mathrm{~g} \mathrm{dm}^{-3}$, aplicados na forma de superfosfato simples). As avaliações referentes aos parâmetros de crescimento foram realizadas mensalmente, durante 6 meses. A colheita das plantas foi realizada aos 180 dias após o transplantio. Os dados foram submetidos à análise de variância e de regressão, com o auxílio do software estatístico Sisvar. O maior crescimento das mudas de cafeeiro foi obtido com doses de $\mathrm{P}$ variando entre 0,6 a $0,9 \mathrm{~g} \mathrm{dm}^{-3}$. Aos 180 dias após transplante, foram verificados os maiores valores de altura de planta, diâmetro do caule e número de folhas.

Palavras-chave: Adubação fosfatada; Nutrição de plantas; Produção de mudas. 
Abstract: The production of seedlings is crucial for the establishment of the coffee culture. Therefore, the objective of this work was to evaluate the growth of seedlings of arabic coffee (Coffea arabica L.) as a function of season and phosphorus doses. The experiment was carried out in a greenhouse of the Department of Plant Science, belonging to the Center of Agricultural Sciences (CCA), Federal University of Paraíba (UFPB), Campus II, Areia, PB, performed in the period of 12/16/2013 to 6/16/2014. Seeds of Arabica coffee matrix plants were used. A randomized complete block design (DBC) was used, with four treatments and four replications, with two plants per plot. The factors consisted of time (30,60, 90, 120, 150 and 180 days) and doses of phosphorus $(0.0,0.3$, 0.6 and $0.9 \mathrm{~g} \mathrm{dm}^{-3}$, applied as single superphosphate). The growth parameters were evaluated monthly for 6 months. The plants were harvested at 180 days after transplanting. The data were submitted to analysis of variance and regression, with the aid of statistical software Sisvar. The highest growth of coffee seedlings was obtained with doses of $\mathrm{P}$ ranging from 0.6 to $0.9 \mathrm{~g} \mathrm{dm}^{-3}$. At 180 days after transplant, the highest values of plant height, stem diameter and number of leaves were verified.

Keywords: Phosphate fertilization, Plant nutrition, Production of seedlings.

\section{Introdução}

A importância da cafeicultura brasileira pode ser visualizada pelo volume de produção, pelo consumo interno, pela sua participação na exportação e capacidade de geração de emprego e renda. O Brasil, atualmente, é o principal exportador e responde por mais de um terço de toda a produção mundial (TATAGIBA et al., 2010).

Um dos fatores que afetam o desenvolvimento do cafeeiro é a qualidade da muda, mudas de baixa qualidade afetam o crescimento e o desenvolvimento da planta, refletindo em baixas produções (AZEVEDO et al., 2014). Entretanto, mudas sadias e bem desenvolvidas constituem, sem dúvida, um dos fatores básicos para o sucesso na formação de novas lavouras (TATAGIBA et al., 2010).

Para produção de mudas de cafeeiro com qualidade superior, certamente a fertilização do substrato é um dos mais importantes fatores, pois, além de promover o crescimento e o desenvolvimento das mudas no viveiro, poderá influenciar no seu estabelecimento no campo (POZZA et al., 2002).

O fósforo é um dos nutrientes que mais limita o crescimento das plantas, principalmente na fase de muda, que apresentam sistema radicular pouco desenvolvido (CARMO et al., 2014), no entanto, quando suprida em fósforo, favorece o desenvolvimento da raiz e o vigor da planta, garantindo assim, a formação do estande, com baixas taxas de replantio (SANTINATO et al., 2014)

David et al. (2008) estudaram a influência de diferentes doses de superfosfato simples, sobre o crescimento de mudas de maracujazeiro amarelo, concluíram que o 
substrato com $40 \%$ de cama de frango, adubado com superfosfato simples, na dose de 7,7 $\mathrm{kg} \mathrm{m}^{-3}$, proporcionou a obtenção de mudas mais vigorosas.

Corrêa et al. (2002) aplicaram fósforo e zinco no desenvolvimento de mudas de aceroleira, afirmaram que as mudas apresentaram incremento linear para as características altura, diâmetro do caule, número de folhas e na massa seca das raízes e da parte aérea, em função das doses de fósforo aplicadas. E a adição de fósforo na dose de $450 \mathrm{mg}$ de $\mathrm{P} \mathrm{dm}^{-3}$ pode melhorar o desenvolvimento das mudas de aceroleiras.

Souza et al. (2007) com o objetivo de estudar a adubação nitrogenada e fosfatada na formação de mudas de tamarindo, concluíram ao final do experimento que as doses de $0,8 \mathrm{~kg} \mathrm{~m}^{-3}$ de nitrogênio com $10,0 \mathrm{~kg} \mathrm{~m}^{-3}$ de fósforo promoveram maior crescimento de mudas; e que a adição de $5,0 \mathrm{~kg} \mathrm{~m}^{-3}$ de fósforo na forma de $\mathrm{P}_{2} \mathrm{O}_{5}$ com a ausência de nitrogênio promoveu a maior massa seca média de raízes.

Diante da relevância que a cultura do café tem para a economia nacional, e da importância do fósforo na nutrição das plantas, esse trabalho teve como objetivo avaliar o crescimento inicial de mudas de café arábica (Coffea arabica L.) em função do tempo e doses de fósforo.

\section{Metodologia}

O experimento foi realizado em casa de vegetação do Departamento de Fitotecnia, pertencente ao Centro de Ciências Agrárias (CCA), da Universidade Federal da Paraíba (UFPB), Campus II, Areia, PB. O experimento foi realizado no período de $16 / 12 / 2013$ a 16/06/2014.

Foram utilizadas sementes de plantas matrizes de café arábica (Coffea arábica L.), oriundas dos cafeeiros do Centro de Ciências Agrárias CCA/UFPB. Os frutos foram coletados completamente maduros, despolpados com auxilio de uma peneira e água corrente, e postos para secar a sombra. As sementes foram semeadas em sementeiras com areia lavada. Posteriormente à emergência, as plântulas foram transplantadas para sacos de polietileno com capacidade para 2,0 litros, contendo como substrato solo coletado na camada de $0-20 \mathrm{~cm}^{-1}$ de profundidade, oriundo do setor de fruticultura do Departamento de Fitotecnia do CCA/UFPB.

O experimento foi conduzido seguindo o delineamento em blocos casualizados (DBC), com quatro tratamentos e quatro repetições, com duas plantas por parcela. Os fatores consistiram em seis épocas de avaliação (30; 60; 90; 120; 150 e 180 dias) e doses 
de fósforo $\left(0,0 ; 0,3 ; 0,6\right.$ e $0,9 \mathrm{~g} \mathrm{dm}^{-3}$, aplicados na forma de superfosfato simples. $\mathrm{O}$ superfosfato simples foi misturado ao solo, até completa homogeneização.

As avaliações referentes aos parâmetros de crescimento foram realizadas mensalmente, durante 6 meses. A altura das mudas foi obtida medindo-se cada planta com régua graduada desde o nível do solo até a gema apical; para aferição do diâmetro do caule, utilizou-se paquímetro metálico, tomando como base o nível do solo, para coleta dos dados; o número de folhas foi obtido através de contagem em cada planta; largura de folhas, determinado com auxílio de régua graduada.

Os tratos culturais utilizados foram: irrigação, controle de pragas e controle das plantas daninhas.

A colheita das plantas foi realizada aos 180 dias após o transplantio, tomando as medidas do comprimento da raiz, por meio de uma régua graduada; em seguida, toda a planta foi colocada para secar em estufas a $65^{\circ} \mathrm{C}$, até a obtenção do peso constante. Posteriormente, procedeu-se a pesagem da massa seca da raiz, e da parte aérea.

Os dados foram submetidos à análise de variância e de regressão, com o auxílio do software estatístico Sisvar (FERREIRA, 2011).

\section{Resultados e Discussão}

As variáveis, altura de planta, diâmetro do caule ao nível do solo e número de folhas, apresentaram comportamento linear crescente, enquanto a variável largura de folha apresentou comportamento quadrático, em função do tempo. Ás variáveis comprimento de raiz, massa da matéria seca da raiz e massa da matéria seca da parte aérea, apresentaram comportamento quadrático. Para a variável altura de plantas (Figura 1), houve crescimento linear independente da dose de fósforo no decorrer do tempo, na qual foi verificado maior altura de plantas aos 180 dias após transplante. Os maiores valores correspondem a 6,68,10,64, 12,74 e $11,39 \mathrm{~cm}^{-1}$ para as doses de 0,0,0,3, 0,6 e $0,9 \mathrm{~g} \mathrm{de} \mathrm{P} \mathrm{dm}^{-3}$, respectivamente. $\mathrm{O}$ maior valor de altura de planta foi encontrado sob influência da dose de $0,6 \mathrm{~g}_{\mathrm{de}} \mathrm{P} \mathrm{dm}^{-3}$.

Marana et al. (2008) avaliando substratos e doses de osmocote ${ }^{\circledR}$ obtiveram altura de plantas de 16,05 cm em tubetes aos 150 dias após a semeadura. Contudo, Santinato et al. (2014) verificou crescimento linear da altura da parte aérea de mudas de cafeeiro até a dose de $1308 \mathrm{mg} \mathrm{dm}^{-3}$ (correspondente a uma dose de $1,3 \mathrm{~g} \mathrm{dm}^{-3}$ ) com valor máximo de $18,6 \mathrm{~cm}^{-1}$, considerando o mesmo tempo de avaliação, divergindo dos 
resultados apresentados nesse trabalho, que mostram o melhor resultado na dose de $0,6 \mathrm{~g}$ $\mathrm{dm}^{-3}$.

Figura 1. Altura de mudas de cafeeiro sob a influência do fósforo. Areia - PB, 2014.

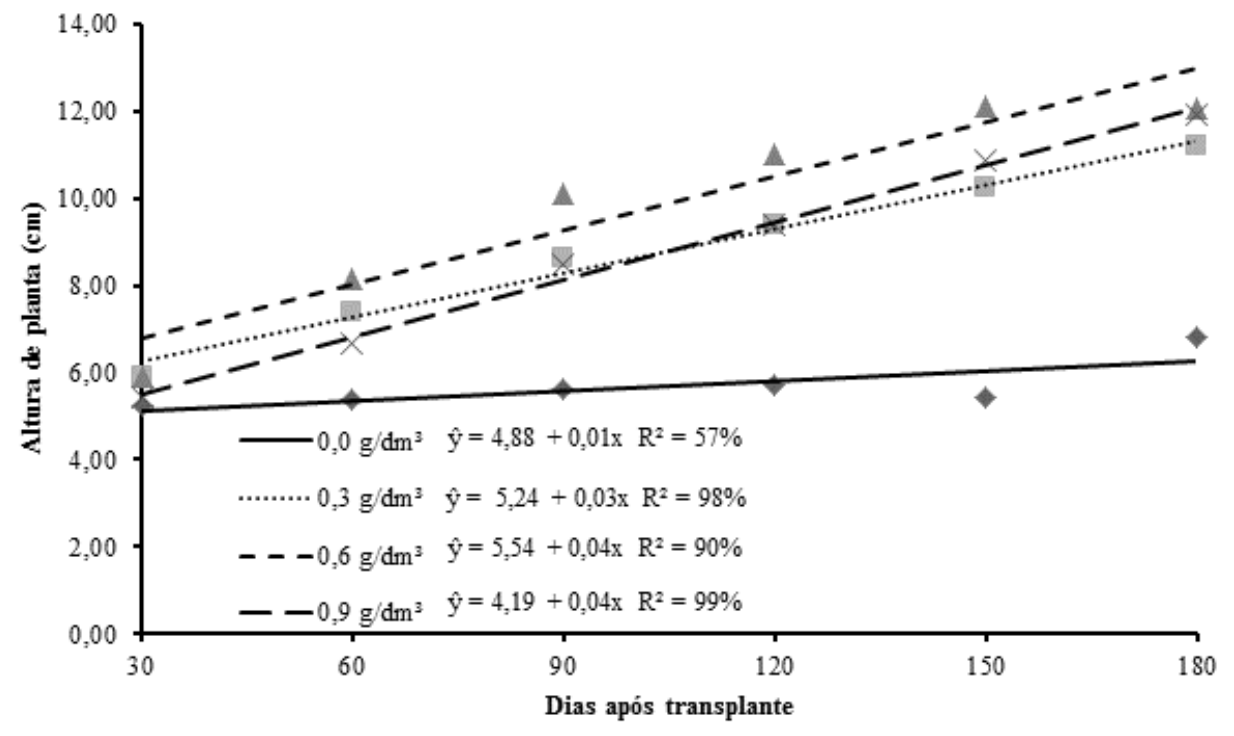

Para a variável diâmetro do caule (Figura 2), houve crescimento linear independente da dose de fósforo ao decorrer do tempo, na qual foi verificado maior altura de plantas aos 180 dias após o transplante. Os maiores valores encontrados foram 1,69, 2,59, 2,83, 2,48 $\mathrm{mm}^{-1}$ para as doses de 0,0, 0,3, 0,6 e 0,9 $\mathrm{g} \mathrm{de} \mathrm{P} \mathrm{dm}^{-3}$, respectivamente. $\mathrm{O}$ maior valor de diâmetro ao nível do solo, foi encontrado sob influência da dose de $0,6 \mathrm{~g}$ de $\mathrm{P} \mathrm{dm}{ }^{-3}$.

Utilizando superfosfato simples como fonte de fósforo, Cogo et al. (2012) encontraram valores de diâmetro do caule variando de 1,57 a $1,67 \mathrm{~mm}^{-1} \mathrm{em}$ mudas de cafeeiro. Considerando que quanto maior o diâmetro do caule maior a chance de sucesso da muda no campo pela resistência de sua parte aérea, este trabalho apresenta valores superior para esta variável. Também, considerando dose de $0,6 \mathrm{~g} \mathrm{dm}^{-3}$, que proporcionou melhor resultado, Santinato et al. (2014) encontraram valor de $2,39 \mathrm{~mm}^{-1}$ de diâmetro do caule, sem a adubação nitrogenada. 
Figura 2. Diâmetro do caule ao nível do solo (DNS) de mudas de cafeeiro sob a influência do fósforo. Areia-PB, 2014.

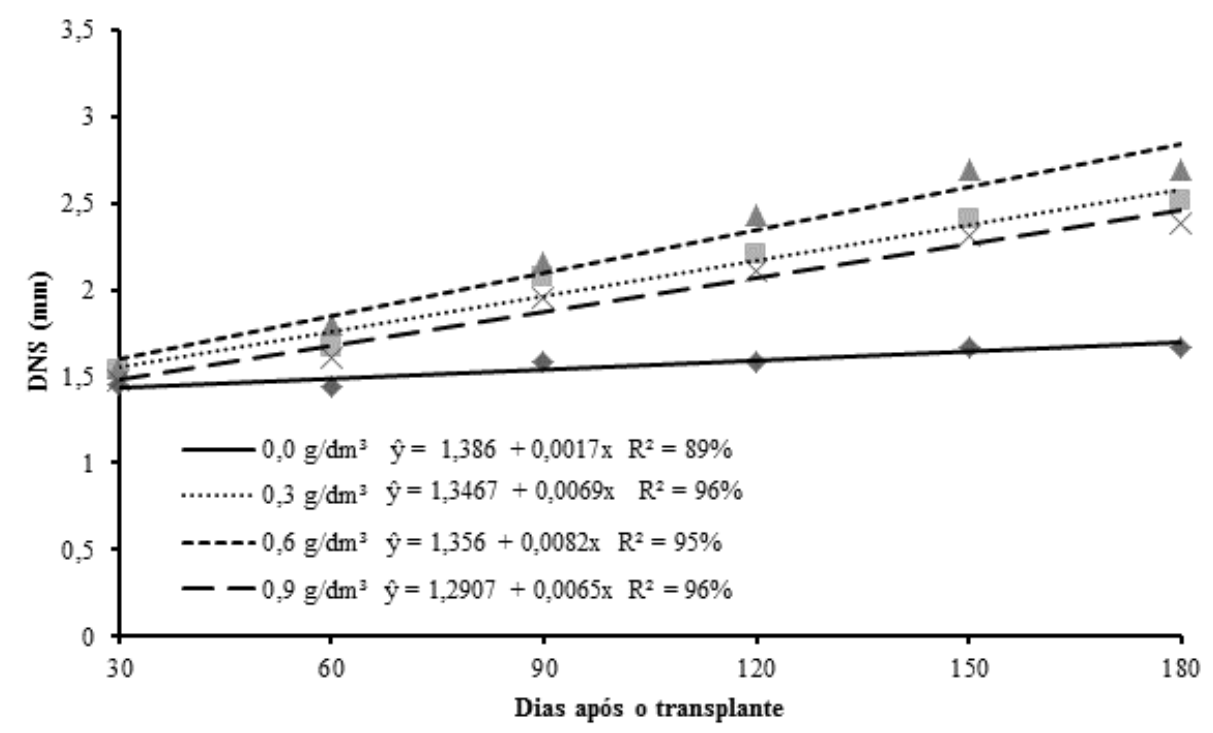

Com relação ao número de folhas (Figura 3), houve decréscimo linear na dose de $0,0 \mathrm{~g} \mathrm{de} \mathrm{P} \mathrm{dm}^{-3}$ e aumento linear para as demais doses de fósforo no decorrer do tempo, na qual foi verificado maior número de folhas aos 180 dias após o transplante. Os maiores valores correspondem a 11,48, 13,47 e 12,34 para as doses de 0,3, 0,6 e $0,9 \mathrm{~g} \mathrm{de} \mathrm{P} \mathrm{dm}^{-3}$, respectivamente. O maior número de folhas foi encontrado sob influência da dose de 0,6 $\mathrm{g}$ de $\mathrm{P} \mathrm{dm}{ }^{-3}$. Na dose de $0,0 \mathrm{~g}$ de $\mathrm{P} \mathrm{dm}^{-3}$, observa-se o valor mínimo de 2,86 folhas aos 180 dias após transplante.

A ausência do fósforo no substrato afetou negativamente a emissão de folhas nas mudas do cafeeiro, sendo observado redução do número de folhas por planta com o decorrer do tempo. Cogo et al. (2012) encontraram valores variando de 3 a 9 folhas em mudas adubadas com superfosfato simples, valores inferiores aos encontrados nesse trabalho. Henrique et al. (2011) encontraram valores médios de 7,4 folhas por plantas em mudas nos tratamentos sem adubação. 
Figura 3. Número de folhas de mudas de cafeeiro sob a influência do fósforo. Areia - PB, 2014.

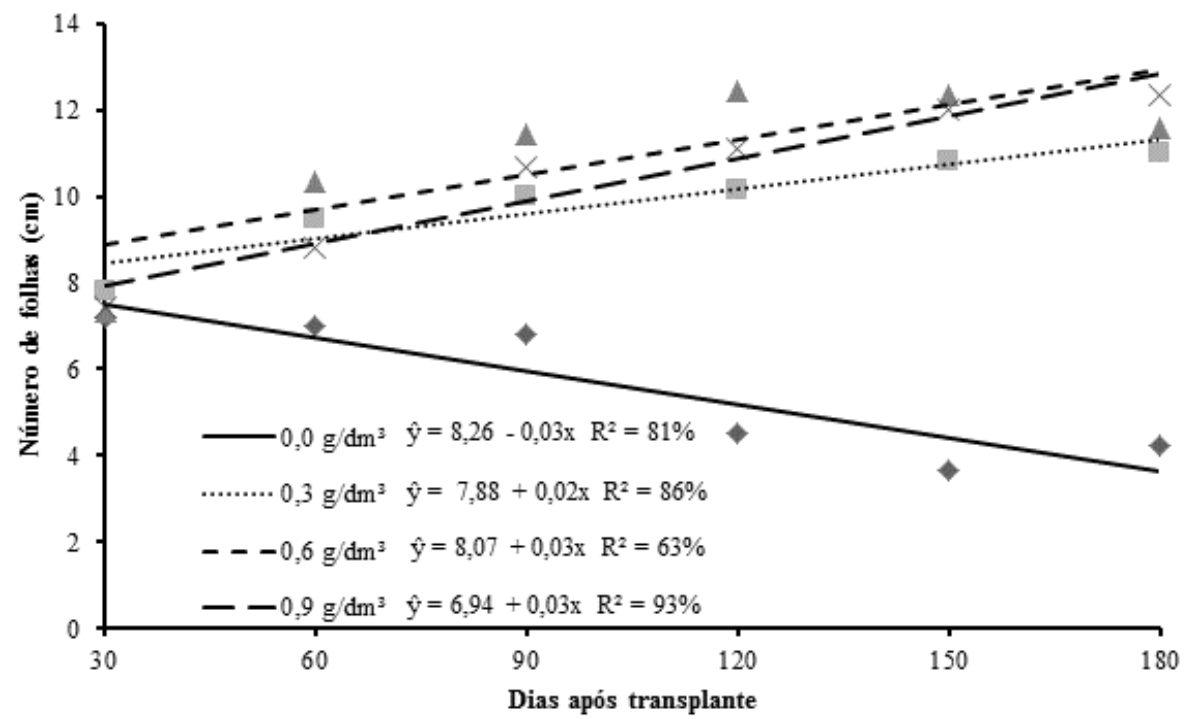

Tratando-se da largura de folhas (Figura 4), houve comportamento quadrático independente da dose de fósforo no decorrer do tempo. Para a dose de $0,0 \mathrm{~g} \mathrm{de} \mathrm{P} \mathrm{dm}^{-3}$, observou-se a maior largura de folhas aos 100 dias, com um valor estimado de $1,7 \mathrm{~cm}^{-1}$. Para a dose de 0,3 $\mathrm{g}$ de $\mathrm{P} \mathrm{dm}^{-3}$, observou-se a maior largura de folhas aos 125 dias, com um valor estimado $3,78 \mathrm{~cm}^{-1}$. Para a dose de $0,6 \mathrm{~g} \mathrm{de} \mathrm{P} \mathrm{dm}^{-3}$, observou-se maior largura das folhas aos 125 dias, com um valor estimado de $5,39 \mathrm{~cm}^{-1}$. Para a dose de $0,9 \mathrm{~g}$ de $\mathrm{P}$ $\mathrm{dm}^{-3}$, observou-se a maior largura de folhas aos 158 dias, com um valor estimado de 3,24 $\mathrm{cm}^{-1}$.

Figura 4. Largura de folhas de mudas de cafeeiro sob a influência do fósforo. Areia - PB, 2014.

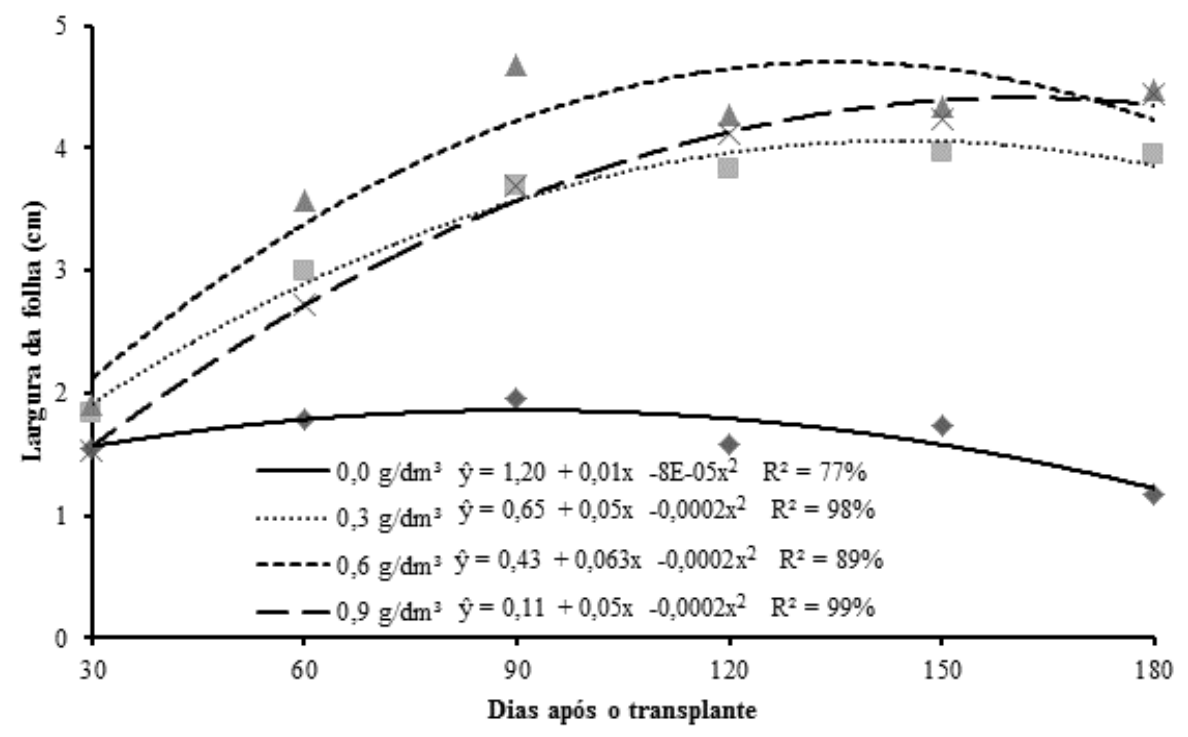


O maior comprimento da raiz (Figura 5) foi verificado aos 83, 150, 140 e 180 dias em função das doses de fósforo $\left(0,0 ; 0,3 ; 0,6\right.$ e $\left.0,9 \mathrm{~g} \mathrm{dm}^{-3}\right)$ respectivamente. $\mathrm{O}$ maior incremento foi verificado aos 140 dias na interação com a dose $0,6 \mathrm{~g} \mathrm{de} \mathrm{P} \mathrm{dm}^{-3}$. O P por ser um nutriente que estimula a expansão do sistema radicular, favorece a absorção dos demais nutrientes presentes no substrato. Silva et al. (2017) trabalharam com fósforo reativo na produção de mudas de maracujá, afirmaram que o aumento da dosagem do fósforo, estimula o crescimento das raízes, garantindo um maior desenvolvimento e vigorosidade da planta quando transplantada para o local definitivo.

Figura 5. Comprimento da raiz aos 180 dias após a semeadura sob a influência do fósforo. Areia - PB,

2014.

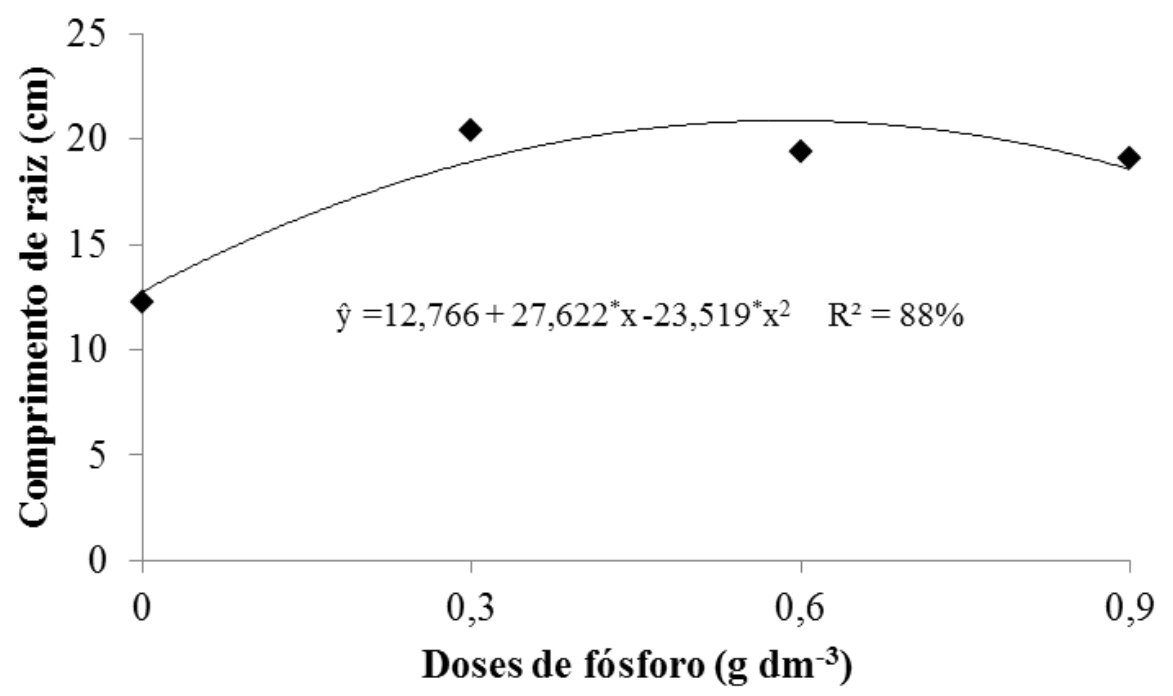

* Significativo a $5 \%$ de probabilidade pelo teste $\mathrm{F}$

As crescentes doses de fósforo proporcionaram aumento sobre a massa da matéria seca da raiz até um ponto ótimo (Figura 6). De tal forma que o maior valor da massa da matéria seca da raiz foi encontrado na dose estimada de $0,66 \mathrm{~g} \mathrm{dm}^{-3}$, a qual proporcionou massa de 0,47 g, apresentando um acréscimo de 371,28\%. Considerando a dose ótima, Carmo et al. (2014) encontraram valores médios de 2,7 g, na avaliação de mudas, sob efeito de doses de fósforo. 
Figura 6. Massa da matéria seca da raiz (MSR) aos 180 dias após a semeadura sob a influência do fósforo. Areia-PB, 2014.

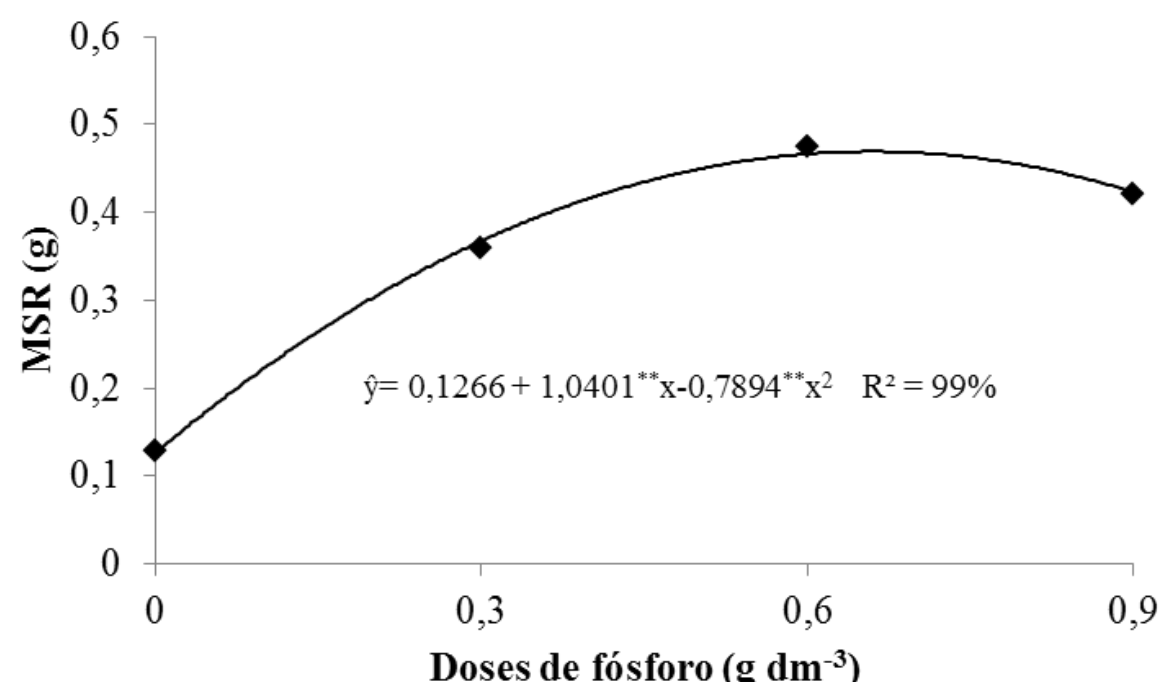

** Significativo a $1 \%$ de probabilidade pelo teste $\mathrm{F}$

As doses de fósforo propiciaram aumento da massa da matéria seca da parte aérea até o ponto ótimo (Figura 7). O maior valor da massa da matéria seca da parte aérea foi encontrado na dose estimada de $0,72 \mathrm{~g} \mathrm{dm}^{-3}$, proporcionando massa de $1,71 \mathrm{~g}$. Refletindo num acréscimo de 1,44 g. Considerando a dose máxima de fósforo, verificase economia de $0,19 \mathrm{~g} \mathrm{de} \mathrm{P} \mathrm{dm}^{-3}$. Cogo et al. (2012) obtiveram peso da matéria seca da parte aérea variando de 0,73 a 1,18 g, testando doses de superfosfato simples na adubação de mudas de cafeeiro.

Figura 7. Massa da matéria seca da parte aérea aos 180 dias após a semeadura sob a influência do fósforo. Areia-PB, 2014.

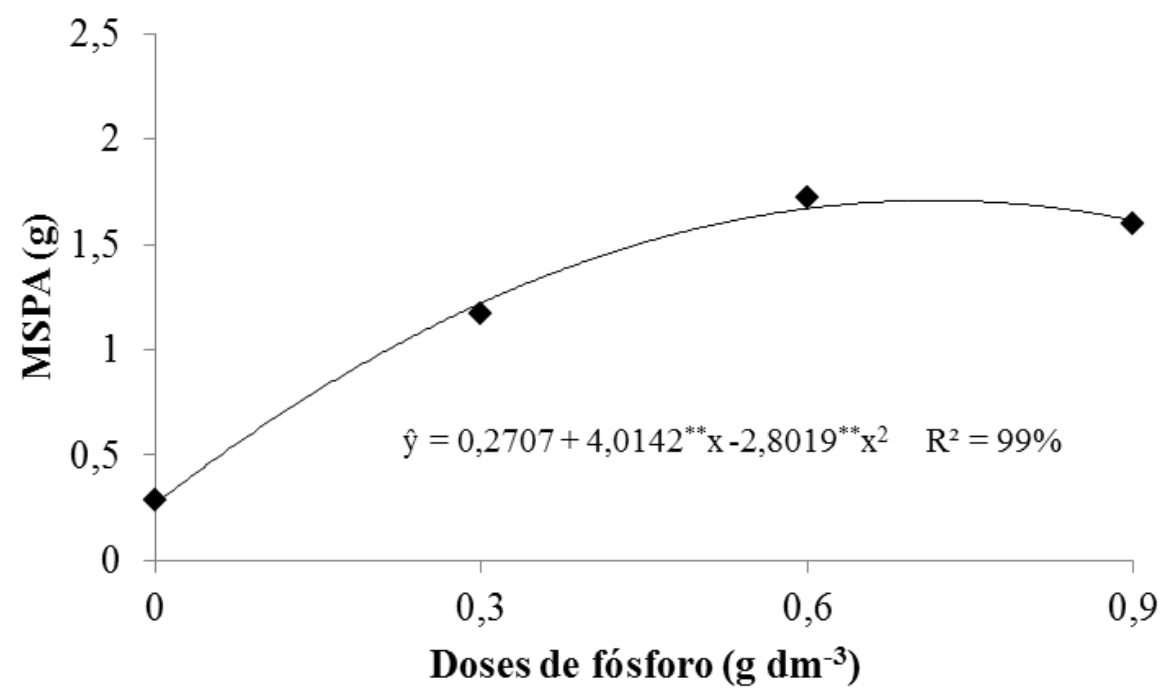

** Significativo a $1 \%$ de probabilidade pelo teste $\mathrm{F}$ 


\section{Considerações finais}

O maior crescimento das mudas de cafeeiro foi obtido com doses de $\mathrm{P}$ variando entre $0,6 \mathrm{a} 0,9 \mathrm{~g} \mathrm{dm}^{-3}$. Aos 180 dias após transplante, foram verificados os maiores valores de altura de planta, diâmetro do caule e número de folhas.

\section{Referências}

AZEVEDO, J. M.; REIS, E. F.; TOMAZ, M. A.; GARCIA, G. O.; NOGUEIRA, N. O.; DARDENGO, M. C. Índices de qualidade e crescimento de mudas de café Conilon sob irrigação e hidrorretentor. Brazilian Journal of Agricultural Sciences. v. 9, n. 3, 2014.

CARMO, D. L.; TAKAHASHI, H. Y. U.; SILVA, C. A.; GUIMARÃES, P. T. G. Crescimento de mudas de cafeeiro recém-plantadas: efeito de fontes e doses de fósforo. Coffee Science, Lavras, v. 9, n. 2, p. 196-206, 2014.

COGO, F. D.; SILVA, E. A; CAMPOS, K. A. Formação de mudas de cafeeiro sob doses crescentes de fósforo. Enciclopédia Biosfera, Goiânia, vol.8, n.14; 2012.

CORRÊA, F. L. O.; SOUZA, C. A. S.; CARVALHO, J. G.; MENDONÇA, V. Fósforo e zinco no desenvolvimento de mudas de aceroleira. Revista Brasileira de

Fruticultura, Jaboticabal - SP, v. 24, n. 3, p. 793-796, Dezembro 2002.

DAVID, M. A.; MENDONÇA, V.; REIS, L. L.; SILVA, E. A.; TOSTA, M. S.;

FREIRE, P. A. Efeito de doses de superfosfato simples e de matéria orgânica sobre o crescimento de mudas de maracujazeiro 'amarelo'. Goiânia, GO, Brasil. Pesquisa Agropecuária Tropical, v. 38, n. 3, p. 147-152, jul./set. 2008.

FERREIRA, D. F. Sisvar: a computer statistical analysis system. Ciência e Agrotecnologia, Lavras, v. 35, n.6, p. 1039-1042, 2011.

HENRIQUE, P. C.; ALVES, J. D.; GOULART, P. D. F. P.; LIVRAMENTO, D. E.; SANTOS, M. O.; SOUZA, K. R. D.; SILVEIRA, H. R. O. Crescimento de mudas de café sob malhas coloridas. In.: Anais..., VII Simpósio de Pesquisa dos Cafés do Brasil. 2011.

MARANA, J. P.; MIGLIORANZA, É.; FONSECA, É. P.; KAINUMA, R. H. Índices de qualidade e crescimento de mudas de café produzidas em tubetes. Ciência Rural, Santa Maria, v.38, n.1, p.39-45, jan-fev, 2008.

POZZA, A. A. A.; GUIMARÃES, P. T. G.; ROMANIELlO, M. M.; POZZA, E. A.; CARVALHO, J. G. Suprimento de fósforo na produção e intensidade da cercosporiose de mudas de cafeeiro em tubetes. Ciênc. agrotec., Lavras. v.26, n.5, p.970-976, set./out., 2002.

SANTINATO, F.; CAIONE, G.; TAVARES, T. O.; PRADO, R. D. M. Doses of phosphorus associated with nitrogen on development of coffee seedlings. Coffee Science, Lavras, v. 9, n. 3, p. 419-426, 2014. 
SILVA, M. R. R.; IGNACIO, L. A. P.; SILVA, G. A. Desenvolvimento de mudas de maracujá amarelo em função de diferentes doses fósforo reativo. Revista de Agronegócio - Reagro, Jales, v.6, n.1, p.41-50, jan./jun. 2017.

SOUZA, H. A.; PIO, R.; CHAGAS, E. A.; RODRIGUES, J. M.; RODRIGUES, H. C. A.; RAMOS, J. D. Doses de nitrogênio e fósforo na formação de mudas de tamarindo. Bioscience Journal, v. 23, n. 1, 2007.

TATAGIBA, S. D., PEZZOPANE, J. E. M., REIS, E. F. Crescimento vegetativo de mudas de café arábica (Coffea arabica L.) submetidas a diferentes níveis de sombreamento. Coffee Science, Lavras, v. 5, n. 3, p. 251-261, 2010. 